\title{
Editorial
}

\section{Optimization Problems via Best Proximity Point Analysis}

\author{
Mohamed Jleli, ${ }^{1}$ Erdal Karapınar, ${ }^{2}$ Adrian Petruşel, ${ }^{3}$ Bessem Samet, ${ }^{1}$ and Calogero Vetro ${ }^{4}$ \\ ${ }^{1}$ Department of Mathematics, College of Science, King Saud University, P.O. Box 2455, Riyadh 11451, Saudi Arabia \\ ${ }^{2}$ Department of Mathematics, Atilim University, Incek, 06836 Ankara, Turkey \\ ${ }^{3}$ Department of Mathematics, Babes-Bolyai University, Kogalniceanu Street No. 1, 400084 Cluj-Napoca, Romania \\ ${ }^{4}$ Università Degli Studi di Palermo, Dipartimento di Matematica e Informatica, Via Archirafi 34, 90123 Palermo, Italy \\ Correspondence should be addressed to Bessem Samet; bessem.samet@gmail.com
}

Received 9 March 2014; Accepted 9 March 2014; Published 28 April 2014

Copyright (C) 2014 Mohamed Jleli et al. This is an open access article distributed under the Creative Commons Attribution License, which permits unrestricted use, distribution, and reproduction in any medium, provided the original work is properly cited.

\begin{abstract}
Many problems arising in different areas of mathematics such as optimization, variational analysis, differential equations, mathematical economics, and game theory can be modeled as fixed point equations of the form $x=T(x)$, where $T$ is a given mapping, in the framework of different kinds of spaces. However, such equations do not necessarily possess a solution especially when $T$ is a nonself mapping. In such situations, it is necessary to find at least one approximate solution $x^{*}$ (called a best proximity point) that is optimal in the sense that the distance between $x^{*}$ and $T\left(x^{*}\right)$ is minimum. Best proximity point analysis (BPPA) deals with the theory (existence, uniqueness stability, and qualitative properties) of the best proximity points.

The aim of this special issue is to bring together the qualified outstanding results and the latest achievements in best proximity point analysis and the related applications. The papers included in this special issue deal with the BPPA in different contexts, such as ordered metric spaces, gauge spaces, Banach spaces without strict convexity property, and hyperconvex metric spaces, as well as for different types of mappings, such as $\alpha$ - $\psi$-contraction mappings, relatively nonexpansive mappings, cyclic mappings, rational proximal contractions, and relatively continuous mappings.

As editors of this special issue, the most difficult problem that we came across was to choose the best papers from the 37 high-quality works. The papers published in this special issue are original and contain some attractive, resourceful, and recognizable ideas. Our motivation in choosing articles for publication in this special issue was whether the submitted papers activate and inspire further scientific activities in the
\end{abstract}

research field of best proximity point analysis and, hence, in that of fixed point theory and its applications.

Mohamed Jleli Erdal Karapinar Adrian Petruşel Bessem Samet Calogero Vetro 


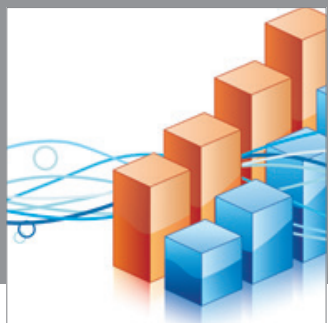

Advances in

Operations Research

mansans

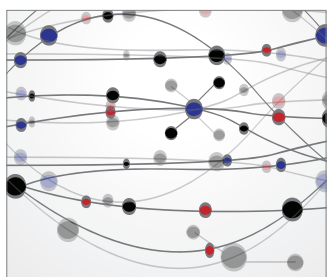

The Scientific World Journal
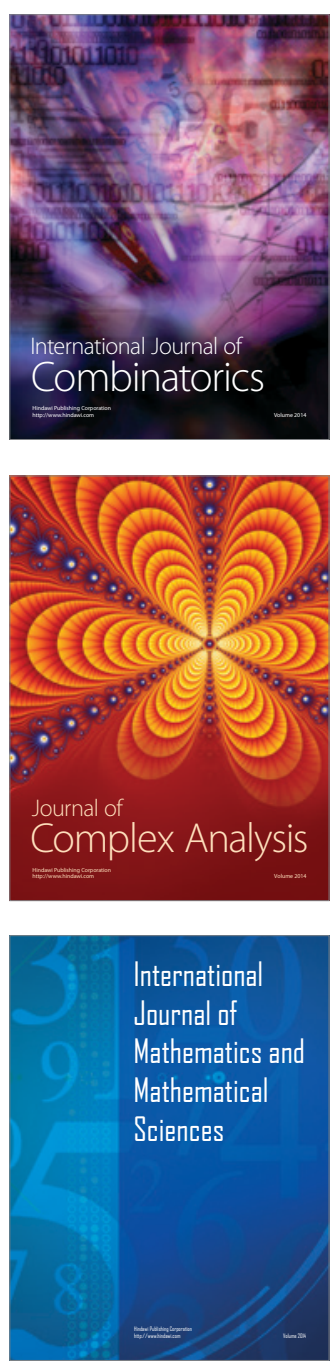
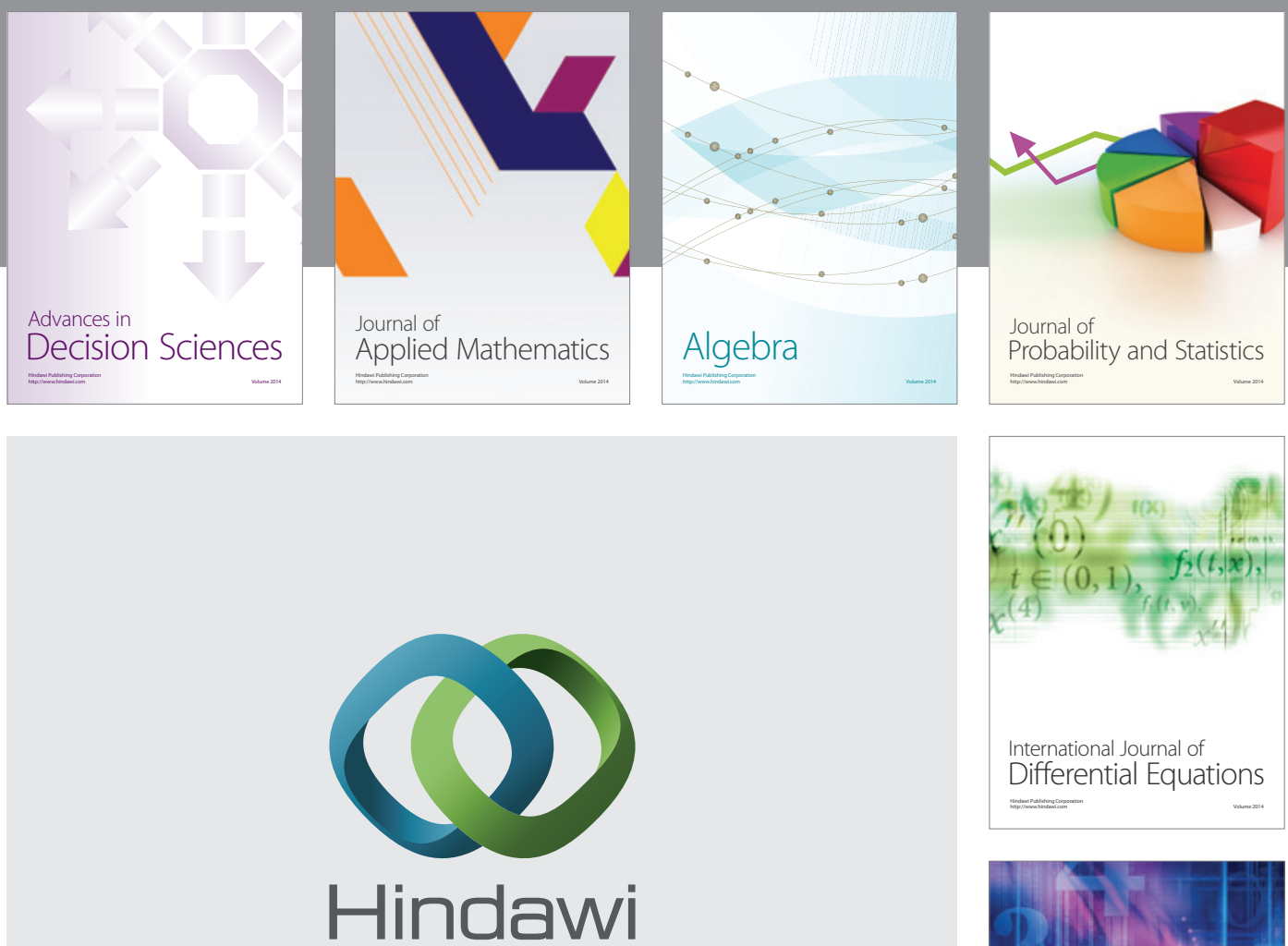

Submit your manuscripts at http://www.hindawi.com
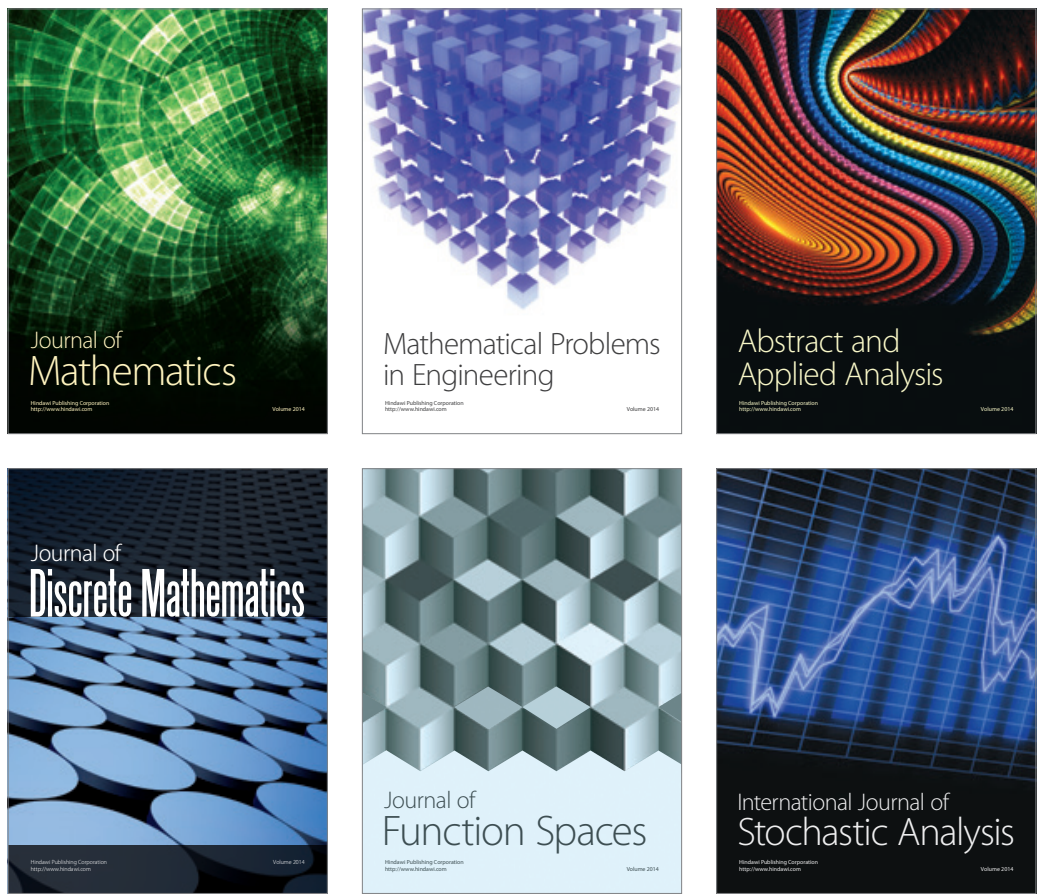

Journal of

Function Spaces

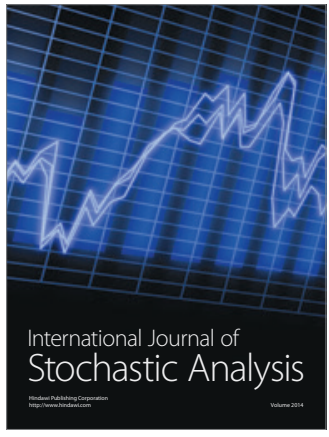

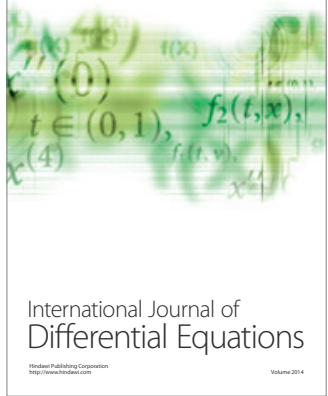
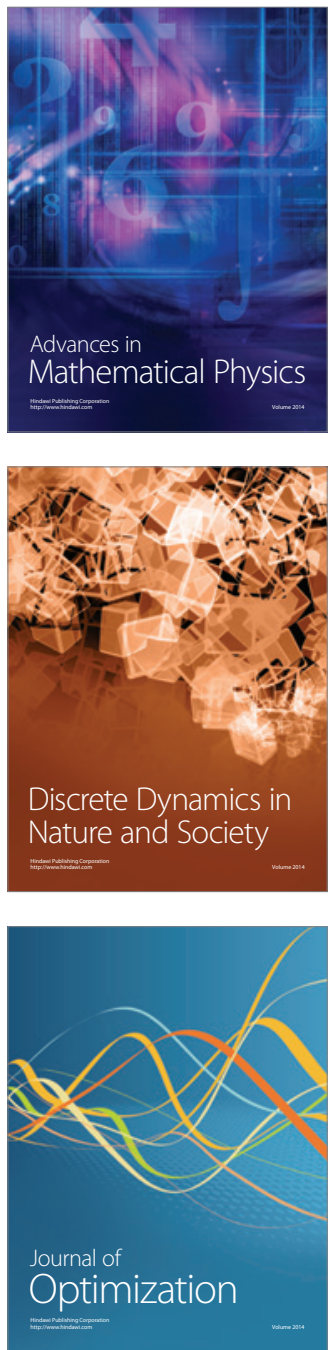